\title{
LITERATURA E HISTORIA (NATURAL) DEL ARTE *
}

\author{
Ana Lia Gabrieloni \\ Universidad Nacional de Río Negro - Sede Andina \\ Consejo Nacional de Investigaciones Científicas y Técnicas \\ alg@ciehum.org.ar
}

Resumen: A partir de la noción musée imaginaire se propone aquí recuperar imaginería serial visual y audiovisual en textos de Virginia Woolf, Roger Caillois, Orham Pamuk, Edmund de Waal y un cortometraje de Rubén Guzmán para examinar cómo el estatuto cultural de estas obras opera la inclusión de sus imágenes en una historia del arte alternativa a la historia canónica del arte, que llamaremos historia natural del arte. La misma restaura la indistinción característica de los antiguos gabinetes de curiosidades, antes de que se estableciera la distinción contemporánea entre museos de arte y museos de ciencias naturales, lo que permite concebir los ya mencionados "museos imaginarios", sitio que admite reunir la inabarcable variedad de cosas y seres que dichas series de imaginería representan, reproduciendo el doble gesto de los mencionados gabinetes, atento al orden del conocimiento que las cosas proporcionan, así como al orden de la estética que su disposición en el espacio museístico requiere. Una de las hipótesis desarrolladas es que la transformación de simples elementos cotidianos, como un trozo de vidrio o una piedra, en imágenes del arte obedece al componente ensayístico de las obras literarias y filmográficas seleccionadas.
Palabras clave: Literatura, Historia del arte, Musée imaginaire, Historia natural, Ensayo.

\begin{abstract}
Based on the notion musée imaginaire this article aims at recovering series of visual and audio-visual imagery in texts by Virginia Woolf, Roger Caillois, Orham Pamuk, Edmund de Waal and a film essay by Rubén Guzmán in order to explore how these works' cultural status incorporates serial imagery into an alternative art history which could be defined as a natural art history. As it reestablishes the lack of differentiation between art and natural history --which characterized ancient cabinets of curiosities before the emergence of contemporary museums-- a natural art history enables us to conceive "imaginary museums" where the broad range of things and beings represented in those textual and filmographic images can be stored on the basis of cognitive and aesthetic principles underlying the display of collections into classical cabinets. One central hypothesis on the reasons for that aesthetical transformation of an everyday object, such as a lump of glass or a piece of stone, relies on the fact that the selected literary and filmographic works comprehend an essayistic component.
\end{abstract}

Keywords: Literature, Art History, Musée imaginaire, Natural History, Essay 
"En materia de arte, la erudición es una suerte de derrota: esclarece lo que escapa a ser lo más delicado, profundiza en lo que no es esencial. Sustituye con sus hipótesis a la sensación, con su memoria prodigiosa a la presencia de la maravilla; y suma al inmenso museo una biblioteca ilimitada.

Venus hecha un documento".

Paul Valéry (1960a, p. 7)

"La aparente inutilidad de hablar sobre el arte acaso esté relacionada con la intensa y constante necesidad que tenemos de hacerlo."

Clifford Geertz (1983, p. 95)

"En gran medida, las fuentes escritas constituyen los textos fundadores."

Agnès Rouveret (Muth et al., 2012, p. 2).

Un caos magnífico, una confusión que obsesiona: así es como Paul Valéry define a los museos. En su interior, al encontrarnos "solos y en medio de tanto arte" — comentanos volvemos superficiales o nos volvemos eruditos (1960a, p. 7). ${ }^{1}$ Tal como puede leerse en el epígrafe que antecede estas líneas, el autor agrega que la erudición, en un contexto semejante, implica un camino sin salida dado que las colecciones de cosas e imágenes del arte se ven desplazadas en importancia por las monografías, tesis y estudios que las mismas suscitan. Nos interesa aquí invertir el problema tradicional que estos últimos escritos buscan resolver a fuerza

${ }^{1}$ En este caso y, a excepción de las obras traducidas al castellano que se consignan en la bibliografía final, las traducciones del inglés y del francés son propias. 
de erudición, cómo otorgar significación cultural a las obras de arte (Geertz, 1983, p. 97), para detenernos a examinar cómo un carácter peculiarmente artístico puede desprenderse de la significación cultural asociada a cosas e imágenes que proponemos - conforman una serie de museos imaginarios escritos, fotografiados y filmados durante el último siglo. Ajenos a la erudición documental, a los archivos y a las bibliotecas que — según Valéry- rivalizan con los museos reales, dichos museos imaginarios consisten en representaciones (imágenes) de cosas o de "objetos sólidos".

Así se titula un cuento de Virginia Woolf, donde el promisorio futuro laboral de un joven llamado John prescribe en tanto él se convierte en presa de una manía por "poseer objetos", que lo lleva a coleccionar piedras y fragmentos de cosas que encuentra al azar en la playa y las calles. Su primer descubrimiento a orillas del mar fue:

un objeto duro —un trozo de materia sólida- [...] un trozo de cristal, tan grueso que resultaba casi opaco. El mar lo había pulido por completo, privándolo de toda arista y toda forma, de tal manera que resultaba imposible decir si había sido botella, vaso o cristal de ventana. No era más que un trozo de vidrio; era casi una piedra preciosa. Bastaba con engastarlo en una montura de oro o ensartarlo en un alambre para transformarlo en una joya; en un colgante o un reflejo verde y apagado en un dedo. (Woolf, 2000, p. 62).

Más tarde, se tropieza a la salida de un edificio con

un fragmento de porcelana de forma sumamente curiosa, más parecido a una estrella de mar que a ninguna otra cosa... tallado, o roto accidentalmente, en cinco puntas 
irregulares pero inconfundibles. $\mathrm{Su}$ tono era predominantemente azul, pero una especie de vetas o manchas cubrían el azul, y unas líneas de color carmesí le conferían una suntuosidad y un lustre de lo más atractivo. (pp. 64-65)

Los paseos de John conducen a los de Austerlitz en la novela homónima de G. W. Sebald. Allí, quien había llegado a Inglaterra como un niño refugiado, durante una caminata a través del cementerio Tower Hamlets, "se había llevado guijarros y hojas de hiedra a casa, también una rosa de piedra y una vez una mano de ángel rota," (2016, p. 230). Como John, Austerlitz sufre de problemas psiquiátricos. No interesa aquí profundizar cómo la melancolía aumenta en ellos a la par que la obsesión por reunir lo disperso inesperado; tampoco en la relación naturalizada a lo largo de muchos siglos entre el coleccionismo y la manía como rasgo patológico de quienes lo practican (Nordsletten et al., 2013, pp. 229-237). Aún cuando ambas concepciones ofrecen legítimas y necesarias vías de lectura de estas dos obras. Lo que, en cambio, llama poderosamente la atención es cómo la "naturaleza ornamental" de simples objetos o desechos se ve agigantada en el contexto de los relatos que contienen las citas anteriores. En resumen, es significativo observar cómo las descripciones que resultan de la mirada de los personajes tienen el poder de transfigurar la naturaleza y los desechos en arte. Una operación que trasciende el plano meramente nominal —en la medida en que, sin duda, descansa sobre composiciones ecfrásticas (es decir, representaciones o figuraciones de las cosas eminentemente verbales) — para incluir el plano material de exhibición de las 
cosas reunidas que, por ejemplo, John dispone en lugares especiales, como la repisa que remata la chimenea en su casa. ${ }^{2}$

El componente ensayístico en "Solid Objects" ayuda a comprender lo anterior. La relevancia que este componente concentra en el relato de Woolf es comparable a la que concentra allí mismo la estética contingente de los objetos representados, y en la que interfiere de modo concluyente la reflexión ensayística. Arribamos así a una suerte de fenomenología germinal de las representaciones literarias que componen esos museos imaginarios que nos interesa reconocer; fenomenología que Woolf evoca al describir el formalismo fundante de la percepción recreadora: "Observado una y otra vez en estado de semi conciencia, la mente ocupada en otras cosas, cualquier objeto se mezcla tan profundamente con el pensamiento, que pierde su forma real y se recompone un poco diferente a como era en el espacio ideal que llega a abstraernos por completo cuando menos lo esperamos" (cursivas nuestras) (2000, p. 63). Esta última interpretación halla su complemento en la noción de Roger Caillois sobre la imaginación como una de las posibilidades concebibles de la materia (1975, pp. 42-43). La fórmula inspira una serie de libros que Caillois escribió durante la segunda mitad del siglo pasado sobre lo que el mismo autor definió como "la otredad lacónica" del mundo mineral (p. 43). Los libros aludidos llevan por título: Pierres (1966), L'Écriture de pierres (1970, Pierres refléchies (1975).

\footnotetext{
2 Para una síntesis sobre la historia conceptual de la écfrasis -en la que J. A. W. Heffernan, W. J. T. Mitchell y Bernard Vouilloux aportaron contribuciones clave- y su impacto en la historia y la crítica del arte, véase nuestro estudio: "Écfrasis" (Gabrieloni, 2008).
} 
No sorprende que autores como Woolf y Caillois conciban las descripciones textuales en términos de una fuerza mimética capaz de penetrar en las cosas del mundo más allá de su apariencia visible para abrazar las experiencias que ellas suscitan en los individuos. En esto radica el componente sensible de "Solid Objects" y los textos de Caillois sobre piedras. Dicho componente ofrece un marco ideal a la transfiguración de imágenes escritas o reproducidas con medios técnicos en robustos museos imaginarios. Por su parte, estos originan una historia del arte alternativa a la tradicional, que proponemos llamar historia natural del arte, en función de la semejanza que esos museos imaginarios conservan en relación con los antiguos gabinetes de curiosidades más que con los modernos museos de arte. Por otra parte, la noción de historia natural del arte tal como se sugiere entenderla aquí, comprende la vida en todas sus expresiones, igual que la historia originada en las ciencias naturales, en contraposición con la "botánica de la muerte" que refiere desde su inicio el ensayo documental codirigido por Chris Marker y Alain Resnais, Les Statues meurent aussi, donde el modelo de la cultura osificada en el interior de los museos de arte tradicionales es puesto en crisis (Huyseen, 1995, p. 13).

Es necesario decirlo con la mayor claridad posible: una historia natural del arte se asienta en museos imaginarios, así como estos pueden asentarse en representaciones verbales y visuales de ocasionales objetos sin valor de mercado, es decir, ajenos a una política de la vida gestionada por la instrumentalidad (Cohen, 2016, p. 11). Con los términos de George Kubler en su providencial libro The Shape of Time. 
Remarks on the History of Things, ver esos objetos ocupando un lugar en la historia canónica del arte sería comparable a ver eslabones ricamente enjoyados y dispersos en una cadena que, no obstante, hecha asimismo con un hilo muy fino, precario, se mantiene entera, si bien imperfecta, a fuerza de un sinnúmero de laboriosas reparaciones (1970, p. 40).

La introducción y preservación de esos eslabones en la narrativa dominante en la historia del arte lleva a quienes asuman tal tarea entre sus manos a experimentar quizá, lo mismo que el espigador mencionado en el libro Hyperion de Hölderlin: "yo atravieso el pasado como un espigador atraviesa un campo después de la siega cosechada por su propietario, recogiendo tan sólo las briznas de paja" (1976, p. 45). Con todo, en el contexto de una historia natural del arte, los restos, fragmentos, despojos, devienen una "luminous debris" semejante a la que arrojan las excavaciones arqueológicas que Gustaf Sobin (2000) evoca en sus magníficos ensayos.

Ahora bien, avancemos diciendo que el ensayismo, ese componente textual que Thomas Harrison (1992) asocia fundamentalmente a autores como Robert Musil y Joseph Conrad, es esencial para que los museos imaginarios textuales y filmográficos contribuyan al desarrollo de una historia natural del arte. En relación con los ensayos de Montaigne, Woolf destaca que "la verdadera prosa es la que posee más poesía" (1925, p. 28). La prosa poética en su versión canónica del poema en prosa mereció el calificativo de oxímoron de parte del crítico Michel Riffattere (1983, p. 117). Woolf anida ideas más existencialistas, menos drásticas sobre la misma: un ensayo, sostiene, es la expresión de la vida interior en 
desacuerdo con la vida exterior. Para Harrison, la solución al conflicto entre "pensar, sentir y actuar" que devino central al clima teórico de nuestra época (p. 29) —donde la experiencia del presente es proléptica e inconclusa- (pp. 222-225), radica en desarrollar una crítica inmanente del conocimiento que, en consecuencia, lo interrogue a éste en su naturaleza auto-crítica (p. 220). Tal desarrollo, agrega, requiere de un paradigma válido tanto en el orden del pensamiento como en el de la acción de los individuos. Desde su perspectiva, el ensayismo proporciona dicho paradigma en términos cognitivos así como éticos, en tanto las ideas y las experiencias de los individuos se combinan ontológicamente en el mismo (p. 4).

En relación con lo anterior, nos preocupa examinar cómo ciertos aspectos ontológicos, es decir: éticos y cognitivos de la noción de ensayismo debida a Harrison, intervienen transformando las narrativas dominantes de la historia del arte con consecuencias notables en la historia de la cultura. El énfasis con que Caillois relativiza la novedad de la abstracción en la pintura vanguardista de principios del siglo pasado, al notar la abstracción naturalmente visible en las rocas y en las alas de las mariposas, pone de manifiesto cómo una escritura en prosa en el límite con la poesía ensaya una apreciación que ejerce un tour de force en la historia del arte tal como suele enseñarse en las academias y universidades. Las ideas de Caillois estimulan a continuar explorando las transposiciones, cuando no falsificaciones que, según el mismo autor, resultan de la complicidad que la naturaleza y los artistas mantienen entre sí (1960, pp. 48, 58). 
Tal como él mismo lo corrobora mediante la comparación entre la abstracción pictórica originada a principios del siglo pasado y la abstracción milenaria alojada en el reino mineral y animal, la naturaleza aparenta estar —en tal sentido- por delante del arte. ${ }^{3}$ En consecuencia, Caillois no duda en invertir el sistema de correspondencias entre lo mineral y lo artístico en los libros sobre piedras. A través de sus páginas saturadas de poéticas descripciones visuales nos sentimos, como John o Austerlitz, embelesados ante la refulgencia con que llegan a revestirse objetos mínimos. Veamos algunos pocos ejemplos en traducción de José Bianco, alusivos a la combinación de cristales en los dos primeros casos, y a los engarces de restos de crustáceos y flora antediluvianos en la piedra, en el tercer y último caso:

Entre las ágatas, hay algunas con venas concéntricas casi rigurosamente paralelas. Los anillos que dibujan siguen, sin adaptarse exactamente, el contorno del nódulo. [...] La pasta espesa se ha helado por capas sucesivas. Sucede frecuentemente que al fin subsiste una gruta tapizada de menudos cristales. Las cinturas concéntricas, desde la más

\footnotetext{
${ }^{3}$ Las fuentes bibliográficas que canonizan el tiempo y el espacio originarios de la abstracción pictórica son vastas y, en consecuencia, casi imposibles de resumir aquí. Nos limitamos a señalar que la misma comprende textos de diversos géneros, desde la tesis doctoral de Wilhelm Worringer titulada Abstraktion und Einfüblung: ein Beitrag zur Stilpsychologie (1908), pasando por el Almanach Der Blaue Reiter de Vassily Kandinsky (1912), y el catálogo intitulado Cubism and Abstract Art que Alfred Barr Jr. publicó en ocasión de la exposición realizada en el Museum of Modern Art de New York entre el 2 y el 19 de abril de 1936, hasta los ensayos que no cesan de consultarse como $A$ Concise History of Modern Painting de Herbert Read (1959), The Story of Art de E. H. Gombrich (1967) y, los más recientes estudios académicos, también en el ámbito sajón, de J. Gage. (1999) Color and Culture: Practice and Meaning from Antiquity to Abstraction; A. Moszynska (1990) Abstract Art y J. Golding. (2000) Paths to Absolute. Mondrian, Malevich, Kandinsky, Pollock, Newman, Rothko, and Still, entre otros.
} 
antigua, aquella que reviste la pared interna de la piedra, se estrechan hasta el borde del vacío. La materia, al enfriarse, se ha contraído. No ocupa ya el espacio entero de su primer volumen. [...] cuando un artesano corta el nódulo en delgadas tajadas, la superficie de cada una de las placas está colmada por el camafeo apretado de los aros. Se presentan desde la periferia rugosa hasta la cavidad central. Tales ejemplares son raros. Entre ellos, los más admirables, a mi parecer, son procurados por aquello en que el color mismo desaparece o más bien sólo proviene de la sombra llevada por la cadencia rápida de la superposición de las zonas. No son ahumados sino de noche. Aparte de algunas zonas dispersas en los bordes, de un negro intenso y sedoso a la vez, el conjunto es de un gris de tinta aguada, nublada, que entorpece la transparencia. La escarcha de los cristales que limitan el paso de las ondas no es más límpido, si es refulgente (1980, p. 103).

lechosa, opaca, de un brillo de porcelana, presenta de tiempo en tiempo manchas del mismo negro de fumagina que la superficie venosa, inmediatamente diáfana, que encierra. Los lazos alternados, al principio relativamente anchos, pierden rápidamente su espesor. Abren una profunda perspectiva de líneas cerradas, rotas, cada vez más cercanas, aunque se confunden casi, en el momento en que el río centelleante pone fin a su vertiginosa procesión inmóvil. [...] En la masa de la substancia viscosa, la fascinación de un volumen plano, liso y cerrado, es decir la reminiscencia del cristal, ha triunfado lentamente. [...] Al fin, cuando no hubo nada extraño en suspenso en una materia limpia, en adelante permeable a la luz y, ante ella sólo el espacio libre, se cumple la promesa. Un erizamiento de pirámides reverberantes florece en los últimos tabiques: el cristal, obsesión de una paciente y secreta alquimia. (1980, pp. 104-06) 
Las grandes amonitas fósiles se parecen a ruedas, a paletas asidas en un espesor mineral que no pudieron remover y que terminó por inmovilizarlas. [...] Un dibujo inmutable permanece, incrustado allí desde hace millones de años. Pero tiene la misma frescura que en el umbral de una larga noche.

Desde esta casi eternidad, sucede que sales metálicas se han alojado en los intersticios de la caparazón calcárea muy pronto arrastrada por las aguas o disuelta en algún líquido voraz. La evaporación, o una reducción aún más severa, convierte un día en metal la envoltura antes desmenuzable secretada por un ser vivo. Un dibujo de plata brilla en adelante en la arcilla o el sílice. Inscribe, en una extensión minúscula, a la vez el presagio de la turbina y la expansión de las nebulosas. [...] Aquí y allá, la cáscara fue rota antes de convertirse en sustancia inalterable: la efigie que resiste a las edades atestigua también más allá de la geología la precariedad de la vida. [...] Flotantes desechos, esparcidos en la piedra, perpetúan sin embargo la primera y perecedera coraza, irrisorio asilo que destruyeron enormes presiones. Han hecho su obra, permitiendo surgir la cifra. (1980, pp. 111-12)

En ocasiones, el reposo de la casi eternidad de las obras debido a los cambios geológicos se ve interrumpido en los sitios arqueológicos. Sobin piensa que, a veces, la arqueología funciona en dirección opuesta a la memoria: cuanto mayor es la envergadura de una excavación, más intacto (o, al menos, más intrínseco) resulta el vestigio hallado. A determinada profundidad, el rastro —fortuito en la superficie- se hace más inequívoco (Sobin 2000, p. 105): "una sola línea implacable que conduce a las personas de forma inexorable hacia lo que permanece siendo ignoto" (Rivette, 1955, p. 194). 
La aparición en la gran pantalla del film Viaggio in Italia (19531954) llevó al autor de esta cita a escribir una carta dedicada por completo a demostrar la contundente modernidad de esta obra de Roberto Rossellini, en tanto la narración se halla en ella desterrada del guion a favor del ensayo. Y este último, según el mismo Jacques Rivette, gozaba de indisputable supremacía como lenguaje del arte moderno, en tanto hacía propias la libertad y la espontaneidad en el terreno de las originales exploraciones formales, temáticas y argumentales que llevaba a cabo (p. 199). Acaso se deba a estas características que la obra, aún en nuestros días, continue considerándose el "primer film moderno" (Mulvey, 2006, p. 113). En él, la memoria, el arte y la arqueología coinciden con la poesía singular de los paisajes culturales y naturales de Nápoles y sus alrededores, hasta fundirse en el hallazgo arqueológico de una pareja que permanecía enterrada bajo las cenizas debido a la erupción del Vesuvio en la antigua Pompeya.

Aun cuando el film inspira toda suerte de reflexiones atinentes a las relaciones entre la poesía, el arte, el ensayo y los museos imaginarios en las cuales sería deseable detenerse, es imprescindible avanzar a fines de completar la serie textual iniciada con Woolf y Caillois, en el marco que trazan esas mismas relaciones. Es el momento pues de considerar otros dos escritores. Uno de ellos es turco; el otro es inglés. El primero, Orhan Pamuk, escribió un libro titulado El museo de la inocencia (2008) al cual luego materializó con la estructura de un museo (2015), donde se exhiben objetos de la vida cotidiana en la ciudad de Estambul, con particular atención a los que 
rodean a los personajes en el mundo de la novela. Ésta, por su parte, incluye fotografías de las vitrinas donde los mencionados objetos están dispuestos a la manera de los antiguos gabinetes de curiosidades; es decir, con un criterio que, taxonómico y estético a la vez, resulta en combinaciones evocativas de la imaginería surrealista. ${ }^{4}$ Creativas variaciones del diálogo textual y visual entre la novela, el museo y los objetos allí reunidos pueden apreciarse sonorizados en el film ensayo dirigido por Grant Gee, The Innocence of Memories (2015). El segundo autor, Edmund de Waal, uno de los ceramistas más prestigiosos de la escena artística actual inglesa, escribió dos libros: The Hare with Amber Eyes (2012) and The White Road. Journey into and Obsession (2015). En ambas obras, las palabras coexisten con las imágenes. En el primer caso, se hallan subordinadas a la historia de una colección heredada, consistente en 264 miniaturas de marfil y madera hechas en Japón [netsuke]. Y, en el segundo caso, al diario de la peregrinación del mismo de Waal a través de tres ciudades clave en la historia de la porcelana en China (Jingdezhen), Alemania (Dresden) e Inglaterra (Cornwall). Las creaciones literario-visuales de Pamuk y de Waal desafían la entidad de los modernos museos de arte, interrogando los intereses subyacentes a la formación de sus colecciones, así como a las funciones que revisten los espacios utilizados para exhibición y depósito de las obras. Dicho con otros términos: el tipo de museos de arte que

\footnotetext{
${ }^{4}$ Además de la bibliografía más adelante consignada, en la nota al pie 7 , se sugiere considerar en relación con el carácter dual, cognitivo y estético, de los antiguos gabinetes de antigüedades los desarrollos teóricos sobre este aspecto de Thomas DaCosta Kaufman (1978).
} 
estamos acostumbrados a frecuentar serían la expresión sintomática de la fosilización de nuestra cultura.

A continuación de una extensa reflexión sobre las vitrinas destinadas a las colecciones de arte privadas, de Waal — que disfruta creando instalaciones donde las piezas de porcelana de su autoría están expuestas detrás de vidrios esmeriladosconcluye: "Me sirvo de esta opacidad porque es preferible mantener guardados los objetos en este estado de fluctuación que a la luz de un museo, como si estuvieran sujetos con alfileres en el interior de una caja sin aire" (2014, p. 210). Asimismo considera que una vitrina, a diferencia de los cajones cubiertos con vidrios donde los objetos se exhiben en los museos como mariposas disecadas, están hechas para ser abiertas (2012, p. 66). La colección de "cosas encontradas, cosas recibidas, cosas exhumadas" (2015, p. 252) que de Waal acostumbraba a ordenar una y otra vez cuando era niño reaparece como uno de sus recuerdos favoritos en los dos libros: "Era mi Wunderkammer, mi mundo de cosas, mi historia secreta del tacto" (2012, p. 350). Allí había "huesos, la piel de un ratón, caracolas, una uña de tigre, la piel mudada de una serpiente, pipas de arcilla y conchas de ostras" junto con "Amonitas, trilobitas, helechos y el hueso coxal de un dinosaurio", provenientes de la colección de minerales y fósiles de fines del siglo XIX que había recibido como obsequio (2015, p. 252). Los gabinetes con colecciones de objetos de la naturaleza y de arte son parte de la historia personal de Waal. Entre sus recuerdos también está la mansión decimonónica de sus ancestros en la ciudad de Dresde, donde un Kunstkammer ocupaba ocho de las numerosas habitaciones existentes. 
Cuanto más nos interiorizamos en los motivos e intereses subyacentes en las obras literarias y artísticas de Pamuk y de Waal, más nos damos cuenta que las mismas se constituyen como "musées imaginaires" que aspiran a re-formar o reformar la comprensión que podamos tener sobre la historia del arte en su conjunto (Didi-Huberman, 2013, p. 168). ${ }^{5}$ A propósito de la noción "museo imaginario", reminiscente en especial del programa estético de André Malraux, se vuelve imprescindible recuperar una vez más algunas de las ideas que entrañan la teoría y crítica del arte de Valéry. En una de sus más sugestivas apreciaciones sobre el célebre retrato titulado Olympia (1863) de Édouard Manet dice: "Su cabeza está vacía: un hilo de terciopelo negro la aísla de lo esencial de su ser. La pureza de un trazo perfecto encierra a la Impura por excelencia," (1960b, p. 1329). Acaso, en el marco de lo que veníamos desarrollando, la presencia de poesía en las descripciones en prosa y del lirismo en el realismo fotográfico o filmográfico de las obras hasta aquí mencionadas concentran una significación máxima en relación con la impura por excelencia, es decir, la vida retratada tal como acontece todos los días. La cruda diversidad de la vida real nos recuerda que, según Malraux, los museos imaginarios tienden a radicalizar la confrontación entre las imágenes a base de sus rasgos diferenciales que, en los museos de arte tradicionales, apenas tiene lugar en una mínima medida (1951, p. 14). La clave para que una obra textual o filmográfica se transfigure en un museo imaginario es el ensayismo, capaz de abrir en esas obras un vacío pleno de resonancias

5 Véase nuestros trabajos sobre "musée imaginaire" en "Historia y crítica del arte. Intento de desnaturalizar sus conversiones recientes" (Gabrieloni, 2018a) y en "Museos reales, ideales e imaginarios de la écfrasis" (Gabrieloni, 2018b). 
autorreferenciales donde la literatura, la fotografía y el cine son medio y objeto al mismo tiempo de un ejercicio o ensayo reflexivo. El ensayismo restituye a los textos y los films la transparencia perdida de la vida cotidiana. Tal como Sebald (2016, p. 91) ha sabido expresarlo: "los colores más hermosos [han] desaparecido ya en su mayor parte o sólo se [encuentran] aún donde nadie los ve, en los jardines submarinos a muchas brazas de profundidad bajo la superficie del mar".

Esta suerte de "mare cognitum" se da a ver en Images of Nowhere, un film ensayo de Rubén Guzmán (2016). Como en la pintura de un paisaje oriental, el agua fluye a lo largo del cortometraje en dirección a su origen y reservorio: la montaña (Yi-Fu Tuan, 1990, p. 128). El mítico Fitz Roy es el objeto privilegiado de contemplación de un inmigrante alemán llamado Ernst Stanhardt que, a inicios del siglo pasado, montó un laboratorio fotográfico en el automóvil con el que recorrió los paisajes patagónicos. En el film se lo escucha leer una carta en alemán dirigida a Aída, la mujer que cuidó de él hasta su fallecimiento. La carta en paralelo a las imágenes nos transportan a un colosal museo de historia natural donde el paisaje, el arte de las piedras chinas, las miniaturas, las citas de Rainer Maria Rilke, George Simmel, Gaston Bachelard, George Steiner, Aleksandr Sokurov, entre otros, el material de archivo e imágenes reales constituyen la base de una reflección ensayística continua, de la cual podemos extraer lo que sigue: "La fotografía, también es una miniatura y, en consecuencia, un abismo que se abre en el espacio, dado que un cambio de escala implica un cambio de realidad". 
El film reconfirma las conversiones que las representaciones ecfrásticas de cosas naturales y objetos operan desde el cine, así como desde la literatura, en el discurso tradicional de la historia del arte en la medida que dichas representaciones conforman genuinos "musées imaginaires", donde la preeminencia de lo diferencial o la condición de otredad de cada cosa y objeto remite con mucha más intensidad a los gabinetes de curiosidades del siglo XVII que a los modernos museos de arte. ${ }^{6}$ En consecuencia, se vuelve necesario indagar cómo ciertos textos literarios desafían la distinción convencional entre cultura y naturaleza - transpuesta a la distinción por completo consolidada entre museos de arte y museos de ciencias naturales - en tanto ambas participan de lo que puede definirse como una historia natural del arte. ${ }^{7} \mathrm{El}$ film ensayo de Guzmán nos transporta a un museo de historia natural tan imaginario como la cascada que Li Cin Chi pintó en la habitación del emperador Suang Sung quien, sin embargo — tal como lo relata la carta de Stanhardt-, pidió que la hicieran desaparecer, ya que el ruido que provocaba le impedía descansar. Es nuestra tarea dedicarnos a reconstruir una

\footnotetext{
${ }^{6}$ Véase J. von Schlosser. (1908), O. Impey y A. MacGregor (1985), K. Pomian (1990), J. Rivallain, J. (2001) y

A. Desvallées y F. Mairesse. (2005).

${ }^{7}$ Clifford Geertz (1983), hacia el final de su ensayo "Art as a Cultural System", reclama la necesidad de "una suerte de historia natural de los signos y los símbolos, una etnografía de los medios de significación" para recuperar el sentido de los sistemas simbólicos sin sacrificar el uso de los mismos — su dimensión performática— y poder así penetrar de algún modo en la "maraña de implicaciones hermenéuticas", disponiéndola en un marco social, donde localizar con "cierta precisión las inestabilidades del pensamiento y del sentimiento" que la puesta en práctica de dichos sistemas genera (p. 45). Con todo, la propuesta metodológica de Clifford difiere de la propuesta aquí, ya que finalmente se sintetiza en lo que el autor llama una "historia social de la imaginación" (p. 119).
} 
historia posible de las cosas que quedan excluidas de los museos.

* Una versión abreviada del presente trabajo se expuso en el $I$ Encuentro de Estudios latinoamericanos sobre Otras literaturas, organizado por el Centro de Estudios en Literatura Francesa y las cátedras de Literatura Europea I y II, y Literatura Contemporánea de la Escuela de Letras de la Facultad de Humanidades y Artes de la UNR, el 19 y 20 de octubre de 2017.

\section{Referencias Bibliográficas}

Barr, A. Jr. (1936). Cubism and Abstract Art. New York: Museum of Modern Art.

Byatt, A. S. et al. (Ed.). (2014). Edmund de Waal. London \& New York: Phaidon Press.

Caillois, G. (1960). Méduse et cie. París: Gallimard. (1980). "Minerales". En Intenciones (pp. 93-111). Traducción de J. Bianco. Buenos Aires: Sur.

Cohen, M. (2016). "El sonido de las cosas. Notas sobre literatura". En Notas sobre la literatura y el sonido de las cosas. Barcelona: Malpaso Ediciones. 
DaCosta Kaufman, T. (1978). "Remarks on the Collections of Rudolf II: The Kunstkammer as a Form of Representatio", Art Journal, 38 (1), pp. 22-28.

Desvallées A. y F. Mairesse (2005). "Sur la muséologie”. Culture \& Musées, (6). pp. 131-155.

Didi-Huberman, G. (2013). L'Album de l'art à l'époque du "Musée imaginaire”. París: Hazan / Musée du Louvre.

Gabrieloni, A. L. (2008). "Écfrasis". Eadem utraque Europa [la misma y la otra Europa]. Revista de historia cultural e intelectual, año 4 (6). Miño y Dávila- UNSAM, Buenos Aires. pp. 83-108.

(2018a). "Historia y crítica del arte. Intento de desnaturalizar sus conversiones recientes”. Armiliar. Revista de Historiografía del Arte (2). pp.1-10.

(2018b). "Museos reales, ideales e imaginarios de la écfrasis”. En A.L. Gabrieloni (Ed.), Interrelaciones entre literatura y arte. América y Europa en las épocas Moderna y Contemporánea. Viedma: UNRN.

Gage, J. (1999). Color and Culture: Practice and Meaning from Antiquity to Abstraction. California: University of California Press.

Geertz, C. (1983). Local Knowlege. Further Essays in Interpretative Anthropology. New York: Basic Books.

Golding, J. (2000). Paths to Absolute. Mondrian, Malevich, Kandinsky, Pollock, Newman, Rothko, and Still. Princeton, NJ: Princeton University Press.

Gombrich E. H. (1967). The Story of Art. London: Phaidon.

Harrison, Th. (1992). Essayism. Conrad, Musil \& Pirandello. Baltimore \& London: The Johns Hopkins University Press.

Hölderlin, F. (1976). Hyperion. Traducción de A. Molina y Vedia y R. Rudna. Buenos Aires: Marymar. 
Huyssen, A. (1995). Twilight Memories: Marking Time in a Culture of Amnesia. New York: Routledge.

Impey, $\mathrm{O}$ y A. MacGregor (Ed.) (1985). The Origins of Museums: The Cabinet of Curiosities in Sixteenth- and Seventeenth-Century Europe. Oxford: Oxford University Press.

Italia Film, Junior Film, Sveva Film (productoras) y Rosselini, R. (director) (1953). Viaggio in Italia [35 mm.]. Italia.

Kandinsky, V. (1912). Almanach Der Blaue Reiter. München: Piper.

Kubler, G. (1970). The Shape of Time. Remarks on the History of Things. New Haven and London: Yale University Press.

Malraux, A. (1951). Les Voix du silence. París: Gallimard.

Moszynska, A. (1990). Abstract Art. London: Thames \& Hudson.

Mulvey, L. (2006). Death $24 X$ a second: Stillness and the Moving Image. New York: Reaktion Books.

Muth, S., R. Neer, A. Rouveret y R. Webb. (2012). "Texte et image dans l'Antiquité: lire, voir et percevoir". Perspective: actualité en histoire de l'art, (2). pp. 218-236.

Nordsletten , A. E. et al. (2013). "Finders keepers: The features differentiating hoarding disorder from normative collecting". Comprehensive Psychiatry, (54). pp. 229-237.

Pamuk, O. (2012). The Innocence of Objects. Traducción de E. Oklap. New York: Abrams.

Pomian, K. (1990). Collectors and Curiosities. Paris and Venice 1500-1800. Cambridge: Blackwell.

Présence Africaine Éditions (productora) y Marker, Ch., Resnais, A., Colquet, G. (directores). 1953. Les Statues aussi meurent [35 mm.]. Francia. 
Beluga, R. (productora) y R. Guzmán, (director) (2016). Images of Nowhere [DVD]. Argentina.

Read. H. (1959). A Concise History of Modern Painting. New York: Praeger.

Riffaterre, M. (1983). Sémiotique de la poésie. París: Seuil.

Rivallain, J. (2001). "Cabinets de curiosité, aux origines des musées”. Outre-Mers. Revue d'histoire, 88 (332-333). pp. 1735 .

Rivette, J. (1985). "Letter on Rossellini". En J. Hillier (Ed.), Cahiers du Cinéma. The 1950s: Neo-Realism, Hollywood, New Wave (pp. 192-204). Traducción de T. Milne. Cambridge, Massachusetts: Harvard University Press.

Sebald, G. W. (2016). Austerlitz. Traducción de M. Sáenz. Barcelona: Anagrama.

Schlosser von, J. (1908). Die Kunst- und Wunderkammern der Spätrenaissance. Leipzig: Verlag von Klinkhardt \& Biermann.

Sobin, G. (2000). "Luminous debris". Reflecting on Vestige in Provence and Languedoc. California: University of California Press.

Tuan, Y. (1990). Topophilia. A Study of Environmental Perception, Attitudes, and Values. New York: Columbia University Press.

Valéry, P. (1960a). “Le Problème des musées”. En J. Hytier (Ed), Euvres. Vol. 1. París: Gallimard.

(1960b). "Triomphe de Manet". En J. Hytier (Ed), Euvres. Vol. 2. París: Gallimard.

Waal, E. de. (2011). The Hare with Amber Eyes. New York: Farrar, Straus and Giroux.

(2015). The White Road. Journey into an Obsession. New York: Farrar, Straus and Giroux. 
Woolf, V. (1925). "Montaigne”. En The Common Reader. New York: Harcourt Brace, 1925. (2000). Selected Short Stories. St. Ives: Penguin.

Worringer, W (1921 [1908]). Abstraktion und Einfühlung: ein Beitrag zur Stilpsychologie. München: Piper. 